\section{CURE OF OVARIAN DROPSY.}

\author{
By John Berna Ro, M.D.
}

Tre subject of ovarian dropsy having been often usefully noticed in THE $L_{\text {Ancer, }}$ and possessing much in terest, the following case, which has been under my eare for more than five years, may be worth publishing, in as much as, pro tınto, it proves the possibility of a radical cure, questions the universality of Sir Astley Cooper's rule and its important deductions, "that there are no absorbents in the ovarian sac," and establishes the value of counter-irritation and of opium, succeeding the free use of depleting means, in local and general inflammation.

$\mathrm{NI} . \mathrm{B}$. aged 34 , after the birth of her seventh child, having been during gestation in good health, and her labour good, discovered a swelling between the short xib at the right side and the spine of the ilium, which gradually increased wlth considerable pain, and at length gave evidence of obscure fluc. tuation; in its progress it extended to the navel, interfering with respiration, producing a variety of hysterical symptoms, but being especially marked by pain and oppression. The boundary of the disease could be well defined, and the presence of the ovarian bag almost felt through the integuments ; otherwise her habit of body was good and not at all broken down, no appearance of swelling, with the above exception, being any where visible. The sequel might induce one to question the accuracy of the diagnosis, and happily there could be no examination to demonstrate it; it rests therefore on symptoms, and authority: the former I have endeavoured to describe", with reference to the latter, she was seen in consultation by two obstetric practitioners in the country, three of the most eminent physicians in Cork, and her case was sent to Dr. Granville of London, and a skilful plyssician in Dublin; all concurred in considering her disease to be ovarian dropsy.

The treatment adopted at first was palliative, on the authority of Sir Astley Cooper and Dr. Bayley, who consider that with the exception of tapping, they do best who take little medicine,

Leeches were frequently applied and mild purgatives administered, but the water accumulating, pain and oppression being very urgent, and her sufferings great, she was tapped four times conseculively in the course of a year and a half, about five quarts being withdrawn each time; her prospects were now very gloomy, as there could not be a reasonable expectation that she could bear up against such continual waste, and it was but too probable the water would periodically accumulate.
The weight deservedly attached to the experience and talents of Sir Astley Cooper, made me hitherto adopt one of two propositions adranced in his lectures, viz. that in the ovarian sac there were no absorbents; because, when he endeavoured to inject it with quicksilver, he never could succeed; and, therefore, there being no hope of removing the fluid by medicines, which could act on the exhalants or kidneys, the abortive effort wonld do an injury, and the sole relief was to be derived from tapping the swelling-" decipit exemplar vitiis irvitabile."

I had hitherto neglected acting on a principle suggested, if not implied, by the above observations, viz. that the prospects of success in this disease were most rationally to be derived from preventing the derivation of blood to the ovarian sac, which elaborated the water; this lady's experience, however, for so much, affirms the possibility, not alone of this, but even that the effused water may be absorbed.

After the last tapping, a large seton was passed through a large space of the integuments near the right groin, and kept constantly open ; a dozen leehes were weekly applied in the diseased neighbourhood for one month; the water accumulated, but more slowly than usual; she now took at night two grains of opium, three of calomel, and three of antimonial power; the first night a copious perspiration set in, which abated pain, and lessened the swelling; she persevered for one month in this course, only omitting the calomel, because it made her mouth sore; as long as there was water in the sac, she was deluged in perspiration at night; at last she completely recovered. It is now more than three years since this recovery; she has enjoyed excellent health, and has frequently travelled with impunity more than forty miles in a day.

Charleville, Cork, Dec. 23, 1829.

MR. GREEN'S CASE OF FRACTURE AND TRANSFUSION OF BLOOD.

\section{To the Editor of THE L ANCET.}

Sir,-Allow me to make a few remarks on the subject of Mr. Green's Clinical Lecture, published in THE $\mathrm{L}_{\mathrm{A} \text { NCET }}$, of December 12 th.

I shall not dwell on the inconclusive reasoning, triteness of remarks, or verbosity of style, so very apparent in it, but when hos. pital surgeons, for the information of their pupils, relate cases of this unfortunate description (unfortunate $I$ mean as relates to the treatment), it behoves them to think well on the subject, before thay scatter their 